\title{
Diseño de un sistema de información web para la gestión cultural
}

\author{
Designing a web information system for heritage management
}

\begin{abstract}
Rosana López CARReño (1), Francisco Javier MARtínez MÉndez (2) y Montserrat López CARReÑo (3)
(1) (2) Facultad de Comunicación y Documentación de la Universidad de Murcia, Campus Universitario de Espinardo, 30100 Murcia, rosanalc@um.es Javima@um.es (3) Consejería de Cultura y Turismo de la Comunidad Autónoma de la Región de Murcia, Palacio González Campuzano, Plaza de Julián Romea 4, 30071 Murcia, montserrat.lopez2@carm.es
\end{abstract}

\begin{abstract}
Resumen
El desarrollo de portales web en el campo de la cultura ha sido muy considerable en los últimos años. No obstante, estos proyectos han carecido de normalización y se han centrado más en la difusión de información acerca de eventos o instituciones que en la gestión de información y la puesta en marcha de servicios para los operadores culturales. Por ello, estos profesionales se ven obligados a buscar otros espacios en la web para desarrollar su actividad: por ejemplo, las redes sociales del entorno de la Web 2.0. Este problema es más serio en los sectores culturales menos desarrollados, como son las artes musicales y escénicas. Este trabajo presenta una propuesta de diseño e implementación de un portal cultural más orientado a la gestión e interacción con los operadores culturales, con el fin de suplir las necesidades informativas-documentales de estos sectores culturales emergentes.
\end{abstract}

Palabras clave: Sistemas de información cultural. Portales culturales. Gestión cultural. Gestión de información. Operadores Culturales. Artes Escénicas, Música. Bases de datos.

\section{Introducción}

La Cultura es un término abstracto en donde se encuadran diferentes disciplinas y artes, donde actúan diversos agentes y donde se desarrollan infinidad de actividades, siendo en el caso español "un factor de desarrollo socioeconómico de primerísima importancia" (Rodríguez Motaró, 2007). Su gestión conlleva el conocimiento de agentes culturales de cualquier tipo, para el apoyo de sus actividades y fomento de las mismas desde las políticas culturales. Dicha actividad heterogénea y fructífera derivada de la gestión cultural produce una voluminosa masa informativo-documental, que al igual que otros ámbitos, se acentúa por el uso de las tecnologías de la información. Desde este punto de vista, se presentan desigualdades en el tratamiento informativo documental que se ha dado

\begin{abstract}
The development of cultural web portals has considerably grown in the last years. However, these projects have lacked standardization and have been more focused on the dissemination of information related with events or institutions than on the management and implementation of services for the cultural operators. Therefore, these professionals are forced to find other eeb sites for their activities, e. $g$. social networks into the Web 2.0 environment. This problem is more serious in the less developed areas, such as musical and scenic arts. This paper presents a proposal for the design and implementation of a cultural portal that is more oriented to the management and interaction with cultural operators, in order to supplement the information needs of these emerging cultural sectors.
\end{abstract}

Keywords: Cultural information systems. Cultural web portals. Cultural management. Information management. Cultural operators. Scenic Arts. Databases.

en los distintos sectores culturales. Si bien en lo relacionado con bienes culturales (Patrimonio, Museos, Archivos, Bibliotecas), existe una tradicional preocupación por la gestión de información (interna y externa) y uso de las tecnologías, avalado y fomentado por organismos públicos y privados; en lo referente a artes musicales y escénicas, la gestión informativo-documental ha sido mucho más precaria y dispersa, orientada casi exclusivamente a actividades de agenda cultural. Los profesionales de este último sector son un nutrido conjunto con unas necesidades informativas carentes de normalización, coordinación y gestión de la información y documentación.

Según las últimas encuestas (Ministerio de Cultura, 2008) hay registrados entre bailarines, coreógrafos, compositores, y cantantes, más de 5.600 y más 3.600 compañías de teatro en el 
territorio nacional, sin contar con otros profesionales vinculados directa o indirectamente, como son, los relacionados con el sonido, iluminación, escenografía, discografía, productores, representación, agencias de comunicación y un largo etc. Otro dato significativo es la celebración de más de 800 festivales de música y concursos de jazz y de más de 850 festivales de teatro durante 2008. Este espectro de profesionales produce una actividad económica relevante en el ámbito geográfico donde actúan, siendo lógico que reclamen apoyo institucional en gestión de información (de ámbito estatal o regional), porque hasta ahora ese apoyo se limitaba a la financiación parcial de la producción artística (1), descuidando tareas de asesoramiento, formación, centralización e intercambio de información. Además, hay que sumar otros agentes culturales que precisan de esta ayuda en materia de gestión y normalización de información, como son los programadores y técnicos de Cultura de las distintas Administraciones Públicas (AAPP) que se alzan como actores principales en la puesta en marcha de políticas culturales (Martinell, Alfons, 1999). En los últimos años, instituciones públicas y privadas vinculadas a la Cultura han empezando a evidenciar estas necesidades informativas y documentales de los profesionales de las artes musicales y escénicas, así como la importancia del uso de las tecnologías para el desarrollo y fomento de su actividad artística, comenzando a desarrollar sistemas de gestión de información cultural, internos y externos, en entorno web.

\section{Sistemas de información culturales y portales culturales}

Un sistema de información cultural debe "responder a las necesidad de contar con información accesible públicamente, sistematizada y generada de manera regular para elaborar diagnósticos, orientar la toma de decisiones y evaluar políticas culturales" (Castellanos Ribot, 2004).

El portal cultural se constituye así en el soporte del sistema de información cultural. Se distinguen tres tipos de portales culturales (Culture.Mondo, 2005):

Portal cultural nacional: busca presentar y/o agregar diversas actividades culturales multidisciplinarias en un país, los cuales incluyen elementos como organizaciones, eventos, información cultural y contenido editorial.

Portal temático: proporciona información regional, nacional o multinacional para disciplinas específicas o sectores culturales como museos o músicos.
Observatorio cultural: realiza investigación cultural y/o desarrollo de políticas colectivas para producir un portal en línea que presente información e investigación de una región, país o grupo de países $y$, en algunos casos, proporciona un ambiente de trabajo digital para los buscadores en la red.

Los portales culturales más extendidos son los temáticos, desarrollados, en su mayoría por administraciones públicas o instituciones regionales. Un ejemplo de ello es el portal cultural de la Región de Murcia, COOLTURA (2).

\section{Propuesta de diseño de un sistema de información para gestión cultural}

El sistema propuesto está orientado en una doble vertiente. Por un lado, suministrar contenido de interés para el público en general, como información sobre organizaciones, eventos, información cultural y editorial a través del portal cultural. Y por otro, la creación de un "Observatorio Cultural", punto de encuentro común entre expertos, profesionales, artistas, técnicos de cultura de las distintas AAPP y encargados de políticas culturales para el intercambio de información y difusión de experiencias culturales. Sería una Intranet de profesionales, artistas y expertos, los cuales estarían registrados para la edición de contenidos en el portal cultural, tanto dentro del observatorio como en el portal para el público en general. Su objetivo es promover la riqueza cultural de un ámbito geográfico concreto, entre los conciudadanos, entre el público en general y entre los profesionales para mostrar la riqueza cultural y su inclusión en la sociedad.

\subsection{Características básicas}

- Estará dirigido al público en general (acceso público) y a los profesionales e interesados en el sector (acceso restringido).

- La gestión y edición del contenido estará descentralizada (bajo supervisión) para garantizar la actualidad y actualización.

- El alta y baja de gestores/editores se realizará bajo solicitud telemática.

- Participación de las administraciones locales y entidades públicas y privadas vinculadas.

- Participación de los artistas, dotando de mayor cobertura a artistas vinculados directamente con el ámbito geográfico que se cubra.

- Cooperación y colaboración con portales turísticos del mismo ámbito geográfico. 


\subsection{Usuarios}

En función de las necesidades informativas, se distinguen varios tipos de usuarios:

- Usuario en general: Es aquel que no precisa de una información puntual y que visita el portal (acceso libre y público), principalmente, para conocer algún dato de alguna actividad cultural.

- Usuario registrado: Es aquel que se registra para poder hacer uso de los servicios de valor añadido de participación disponibles en el portal, como comentar noticias, eventos, etc., participar en foros, realizar votaciones o valoraciones, etc. (acceso restringido y público). Para su registro, se exigirán datos mínimos como nombre, mail, password y provincia.

- Editores: Usuarios que dispondrán de distintos permisos (según el perfil) para editar contenido tanto en Internet como en la Intranet del portal. Estos usuarios serán los que conformarán el "Observatorio Cultural" e intercambiaran información específica y técnica sobre actividades culturales (acceso restringido y privado).

\subsection{Arquitectura de la información}

El sistema de información estará basado en dos bases de datos (BD) principales: BD Directorio y BD Agenda, auxiliadas por otras BBDD, como BD Tablón y BD Prensa.

Ambas BBDD usaran las mismas categorías para clasificar la información y que son: artes escénicas, artes plásticas y visuales, cine y arte visual, cómic, cultura popular y tradicional, fotografía, interculturalidad, literatura, multiculturalidad, música, patrimonio, y performance teatro.

\subsubsection{BD Directorio}

Está estructurada por perfiles que pueden contener campos comunes (con asterisco) o específicos:

- Gestores y programadores: incluyendo técnicos de cultura, responsables de políticas culturales a nivel local y autonónico, programadores de salas.

- Empresas y profesionales: personas físicas y jurídicas auxiliares a la organización, producción, realización, difusión, etc. de eventos culturales.

- Artistas y compañías: profesionales artísticos de todos los ámbitos culturales.

\begin{tabular}{|c|c|}
\hline Campo & Descripción \\
\hline$\cdot \mathrm{ID}^{*}$ & Número de identificación único \\
\hline - Nombre * & Y apellidos \\
\hline - Mail (R) * & Mail del gestor o programador \\
\hline - Puesto & Desempeñado en su entidad perteneciente \\
\hline - Entidad & Pública o privada \\
\hline - Dirección * & $\begin{array}{c}\text { Postal para posible envío de información o } \\
\text { publicidad }\end{array}$ \\
\hline - Población * & Dónde desempeña su actividad \\
\hline - Telf. Fijo * & En la entidad \\
\hline - Telf. Móvil & Opcional \\
\hline - Fax * & En la entidad \\
\hline - Sector & $\begin{array}{l}\text { Puede ser: público / privado (menú } \\
\text { desplegable) }\end{array}$ \\
\hline - Categoría * & $\begin{array}{c}\text { Indicada anteriormente (menú } \\
\text { desplegable) }\end{array}$ \\
\hline - Etiquetas * & $\begin{array}{c}\text { Palabras clave para el servicio "nube de } \\
\text { etiquetas" }\end{array}$ \\
\hline - Observ * & Campo de texto \\
\hline
\end{tabular}

Tabla I. Campos de la BD Directorio: Perfil Gestores y programadores.

\begin{tabular}{|c|c|}
\hline Campo & Descripción \\
\hline$\cdot \mathrm{ID}^{*}$ & Número de identificación único \\
\hline Nombre * & Y apellidos \\
\hline - $\mathrm{CIF} / \mathrm{NIF}$ & De la empresa o profesional \\
\hline Mail $(\mathrm{R}){ }^{*}$ & Mail de la empresa o profesional \\
\hline Web & De la empresa o profesional \\
\hline - Dirección * & Postal para envíos \\
\hline - Población * & Dónde desempeña su actividad \\
\hline Telf. Fijo * & C \\
\hline - Telf. Móvil * & Opcional \\
\hline - Fax * & Emergentes \\
\hline - Contacto & Nombre de la persona de contacto. \\
\hline $\begin{array}{l}\text { - Cargo- } \\
\text { contacto }\end{array}$ & Puesto que desempeña en la empresa \\
\hline Categoría * & $\begin{array}{c}\text { Indicada anteriormente (menú } \\
\text { desplegable) }\end{array}$ \\
\hline Descripción & $\begin{array}{l}\text { Campo de texto para resumir las } \\
\text { actividades principales de la empresa }\end{array}$ \\
\hline Actividad (R) & $\begin{array}{c}\text { (Menú desplegable): } \\
\text { Asociaciones. Colectivos. Cineastas. } \\
\text { Comunicación. Discográficas. } \\
\text { Distribuidores. Escenarios y carpas. } \\
\text { Escenografías. Estudios de grabación. } \\
\text { Fijación de carteles. Iluminación. Otros. }\end{array}$ \\
\hline Etiquetas * & Palabras clave para "nube de etiquetas" \\
\hline - Observs. * & Campo de texto \\
\hline
\end{tabular}

Tabla II. Campos de la BD Directorio. Perfil Empresas/Profesionales.

\footnotetext{
- Salas e instalaciones: incluyendo información de localización, contacto, información técnica, aforo, etc.
}

En las siguientes tablas se indican los campos a mostrar en función del perfil. Algunos de dichos campos pueden ser repetibles y serán indicados con la anotación (R). Los campos que comien- 
zan con un punto nego sólo se mostraran en la zona restringida.

\begin{tabular}{|c|c|}
\hline Campo & Descripción \\
\hline$\cdot \mathrm{ID}^{*}$ & Número de identificación único \\
\hline Nombre * & Del artista o compañía \\
\hline - ClF/NIF & $\begin{array}{l}\text { Del artista, compañía o de la } \\
\text { persona o entidad que factura }\end{array}$ \\
\hline Web-Oficial & URL oficial del artista o compañía \\
\hline Myspace & URL Myspace artista/compañía \\
\hline YouTube & URL YouTube artista/compañía \\
\hline Facebook & URL Facebook artista/compañía \\
\hline - $\mathrm{N}^{\circ}$-componentes & $\begin{array}{l}\mathrm{N}^{\circ} \text { de personas que forman la } \\
\text { agrupación o compañía }\end{array}$ \\
\hline - Mail (R) * & Mail artista/compañía \\
\hline - Contacto & $\begin{array}{l}\text { Nombre y apellidos de la persona de } \\
\text { contacto }\end{array}$ \\
\hline - Puesto & $\begin{array}{l}\text { Desempeñado de la persona de } \\
\text { contacto (manager, booking, etc) }\end{array}$ \\
\hline - Mail- contacto & $\begin{array}{l}\text { Correo de la persona de contacto } \\
\text { (manager, booking, etc) }\end{array}$ \\
\hline - Dirección * & $\begin{array}{l}\text { Postal para posible envío de } \\
\text { información o publicidad }\end{array}$ \\
\hline Población * & Residencia del artista/compañía \\
\hline - Telf. Fijo * & Del artista, compañía o contacto \\
\hline - Telf. Móvil * & Opcional \\
\hline - Fax * & Del artista, compañía o contacto \\
\hline Descripción & $\begin{array}{c}\text { Breve del artista o compañía: } \\
\text { trayectoria, actuaciones relevantes, } \\
\text { premios, etc. }\end{array}$ \\
\hline Categoría * & $\begin{array}{c}\text { Indicada anteriormente (menú } \\
\text { desplegable) }\end{array}$ \\
\hline Etiquetas * & $\begin{array}{l}\text { Palabras clave para "nube de } \\
\text { etiquetas". Estilos (Pop-rock, Funky, } \\
\text { Flamenco, Hip-Hop, Jazz-Blues, } \\
\text { etc.), Tipo formación (Cantautor, } \\
\text { Banda/Grupo, etc.) }\end{array}$ \\
\hline Dossier & $\begin{array}{c}\text { Documento para prensa de } \\
\text { presentación y descripción extensa } \\
\text { del artista o grupo }\end{array}$ \\
\hline Imágenes & $\begin{array}{l}\text { Posibilidad de inserción de ficheros } \\
\text { gráficos (5 máximo) }\end{array}$ \\
\hline Audio & $\begin{array}{l}\text { Posibilidad de inserción de ficheros } \\
\text { de audio y de reproducción ( } 5 \\
\text { máximo). }\end{array}$ \\
\hline Vídeo & $\begin{array}{c}\text { Posibilidad de inserción de ficheros } \\
\text { de vídeo, reproducción o enlace a } \\
\text { youtube ( } 5 \text { máximo) }\end{array}$ \\
\hline Material & $\begin{array}{c}\text { Indicar el tipo de material } \\
\text { promocional del que dispone el } \\
\text { artista o compañía }\end{array}$ \\
\hline Observaciones * & $\begin{array}{l}\text { Campo de texto para hacer las } \\
\text { indicaciones oportunas }\end{array}$ \\
\hline
\end{tabular}

Tabla III. Campos de la BD Directorio: Perfil Artistas/Compañias.

\begin{tabular}{|c|c|}
\hline Campo & Descripción \\
\hline - ID * & $\begin{array}{c}\text { Número de identificación único. Lo } \\
\text { asigna el sistema de forma } \\
\text { automática. }\end{array}$ \\
\hline Nombre * & $\begin{array}{c}\text { De la sala, instalación o ubicación } \\
\text { física }\end{array}$ \\
\hline Tipo & $\begin{array}{c}\text { (Menú desplegable) } \\
\text { Archivos. Auditorios. Bibliotecas. } \\
\text { Casas de cultura. Centros } \\
\text { culturales. Centros sociales. } \\
\text { Galerías de arte. Locales de } \\
\text { ensayo. Museos. Otros espacios. } \\
\text { Pabellones. Salones de actos. } \\
\text { Salas de conciertos. Salas de } \\
\text { exposiciones. Teatros. }\end{array}$ \\
\hline Mail $(R) *$ & $\begin{array}{l}\text { Correo electrónico de la sala, } \\
\text { instalación o ubicación física }\end{array}$ \\
\hline Web & $\begin{array}{c}\text { Oficial de la sala, instalación o } \\
\text { ubicación física }\end{array}$ \\
\hline Dirección * & $\begin{array}{c}\text { De la sala, instalación o ubicación } \\
\text { física }\end{array}$ \\
\hline Población * & $\begin{array}{c}\text { De la sala, instalación o ubicación } \\
\text { física }\end{array}$ \\
\hline - Contacto & $\begin{array}{c}\text { Nombre de la persona de contacto } \\
\text { en la empresa }\end{array}$ \\
\hline - Cargo-contacto & $\begin{array}{c}\text { Puesto que desempeña en la } \\
\text { empresa }\end{array}$ \\
\hline - Telf.-contacto & De la sala/espacio \\
\hline - $N^{0} \operatorname{fax}^{*}$ & De la sala/espacio \\
\hline Categoría * & $\begin{array}{c}\text { Indicada anteriormente (menú } \\
\text { desplegable) }\end{array}$ \\
\hline • Descripción & $\begin{array}{l}\text { Campo de texto con información } \\
\text { general y técnica de la sala, } \\
\text { instalación o ubicación física }\end{array}$ \\
\hline Logo & $\begin{array}{l}\text { Imagen o gráfico de la sala, } \\
\text { instalación o ubicación física }\end{array}$ \\
\hline Programación & $\begin{array}{c}\text { Documento descargable sobre el } \\
\text { programa de la sala, instalación o } \\
\text { ubicación física }\end{array}$ \\
\hline Aforo & $\begin{array}{l}\text { Capacidad en } n^{\circ} \text { de personas en la } \\
\text { sala/espacio }\end{array}$ \\
\hline Alquiler & Sí/No \\
\hline Tarifa & $\begin{array}{c}\text { Indicar el importe por el alquiler de } \\
\text { la instalación, especificando si es } \\
\text { por horas o por día }\end{array}$ \\
\hline - Rider & $\begin{array}{l}\text { Documento descargable sobre la } \\
\text { disposición técnica de la } \\
\text { sala/espacio y ubicación física } \\
\text { (luces, sonido, escenario, etc.). }\end{array}$ \\
\hline Cómo llegar & Coordenadas GPS \\
\hline Etiquetas * & $\begin{array}{l}\text { Palabras clave para "nube de } \\
\text { etiquetas" }\end{array}$ \\
\hline - Observaciones * & Campo de texto \\
\hline
\end{tabular}

Tabla IV. Campos de la BD Directorio: Perfil Salas/Instalaciones.

\subsubsection{BD Agenda}

En principio, solo habría un único perfil vinculado al resto de perfiles de la BD directorio, a saver, Festivales y Eventos: certámenes, recitales, festivales, etc. 


\begin{tabular}{|c|c|}
\hline Campo & Descripción \\
\hline$\cdot \mathrm{ID}^{*}$ & Número de identificación único \\
\hline Nombre * & Título del festival o evento \\
\hline Artista/s & $\begin{array}{c}\text { Nombre/s del artista/s (vinculado con } \\
\text { tabla "Artistas/Compañías") }\end{array}$ \\
\hline Mail (R) * & Mail del festival o evento \\
\hline Web & Oficial del festival o evento \\
\hline Lugar & $\begin{array}{c}\text { Instalación del evento (vinculado con } \\
\text { tabla "Salas/instalaciones") }\end{array}$ \\
\hline Dirección * & Dirección postal sede evento \\
\hline Población * & Dónde desempeña su actividad \\
\hline - Organizador & $\begin{array}{c}\text { Entidad responsable de la realización } \\
\text { del festival o evento }\end{array}$ \\
\hline - Contacto & Persona de contacto en la empresa \\
\hline - Cargo-contacto & Puesto que desempeña \\
\hline - Telf.-contacto & De empresa/contacto \\
\hline Categoría * & $\begin{array}{c}\text { Indicada anteriormente (menú } \\
\text { desplegable) }\end{array}$ \\
\hline Descripción & $\begin{array}{l}\text { Campo de texto con información } \\
\text { general sobre el festival o evento }\end{array}$ \\
\hline Tipo & $\begin{array}{c}\text { (menú desplegable). } \\
\text { Recitales, Conciertos, Festivales, etc. }\end{array}$ \\
\hline Cartel/Logo & $\begin{array}{c}\text { Imagen gráfica del cartel de la última } \\
\text { edición del festival/evento }\end{array}$ \\
\hline Programación & $\begin{array}{l}\text { Documento descargable sobre el } \\
\text { programa del festival/evento }\end{array}$ \\
\hline $\begin{array}{l}\text { Plazo cierre- } \\
\text { programación }\end{array}$ & $\begin{array}{l}\text { Fecha aproximada de cierre de la } \\
\text { programación del festival/evento }\end{array}$ \\
\hline $\begin{array}{l}\text { Plazo inicio- } \\
\text { propuestas }\end{array}$ & $\begin{array}{l}\text { Fecha de comienzo de recepción de } \\
\text { propuestas de artistas para participar } \\
\text { en el festival/evento }\end{array}$ \\
\hline $\begin{array}{l}\text { Plazo fin- } \\
\text { propuestas }\end{array}$ & $\begin{array}{l}\text { Fecha límite de recepción de } \\
\text { propuestas de artistas para participar } \\
\text { en el festival/evento }\end{array}$ \\
\hline Fecha inicio & Del festival/evento \\
\hline Fecha fin & $\begin{array}{l}\text { Del festival/evento. Es también la } \\
\text { fecha de caducidad del anuncio }\end{array}$ \\
\hline Hora inicio & Del festival/evento \\
\hline Cómo llegar & Coordenadas GPS \\
\hline Portada & $\begin{array}{l}\text { Cuadro de validación (Sí/No) para } \\
\text { colocar en evento en la página } \\
\text { principal de la agenda }\end{array}$ \\
\hline Etiquetas * & $\begin{array}{l}\text { Palabras clave para "nube de } \\
\text { etiquetas" }\end{array}$ \\
\hline - Observaciones * & Campo de texto \\
\hline
\end{tabular}

Tabla V. Campos de la BD Agenda. Perfil Festivales/Eventos.

Igual que en las tablas anteriores, en la tabla $\mathrm{V}$ se han indicado los campos a mostrar en función del perfil. Algunos de dichos campos pueden ser repetibles y se indican con la anotación (R). Los campos con un punto negro delante sólo se mostraran en la zona restringida.

\subsection{3. $B B D D$ auxiliares}

La base de datos Tablón, en principio, solo dispondrá de un único perfil que estará vinculado al resto de perfiles de la BD Directorio y se constituirá como un espacio para anunciar convocato- rias por parte de las administraciones públicas. Además, los usuarios registrados podrán insertar e intercambiar información relativa al sector.

Por otro lado, en la base de datos Prensa recopilará notas de prensa y artículos relacionados con la cultura (en el ámbito público y privado), tanto en medios regionales, como nacionales e internacionales. Esta tarea se realizará mediante la captura de feeds (RSS) de medios de comunicación que dispongan de este servicio. La revisión y selección de las noticias se realizará por parte del gabinete de prensa para su posterior publicación definitiva en el portal.

\subsection{Creación y mantenimiento de contenidos}

En la fase de puesta en marcha del sistema, la alimentación se realizará de forma manual y centralizada a través del equipo documentalista para dotar de un contenido básico al portal cultural. Los primeros datos a introducir procederán de las fuentes impresas localizadas y facilitadas por responsables de las políticas culturales públicas, además de las facilitadas por los distintos organismos culturales públicos.

En una segunda fase, la alimentación se continuará realizándose manualmente, pero la carga de inserción de contenido no se centralizará en el equipo de documentación, sino que se descentralizará través de los distintos perfiles y niveles de gestores de contenido indicados anteriormente. El equipo documentalista realizará, por tanto, tareas de supervisión y coordinación del contenido insertado en el portal, garantizando la idoneidad y calidad del mismo.

Al mismo tiempo que se realizará la alimentación manual descentralizada, se llevará a cabo una alimentación automática, por medio de la importación de datos desde otras fuentes, tanto gratuitas - como puede ser el caso de importación de datos de otros sistemas pertenecientes a organismos y temática vinculados, como por ejemplo portales turísticos o a través de los alimentadores de contenido o RSS-, así como de fuentes o contenidos contratados, como puede ser el caso de la adquisición de contenido a guías de ocio (3), en cuyo caso habrá que valorar su adecuación. En este tipo de alimentación es precisa una revisión y validación de los contenidos obtenidos de forma automática, antes de su publicación definitiva en el portal.

\subsection{Conclusiones}

Las nuevas necesidades informativo-documentales por parte de algunos sectores culturales han propiciado la creación de sistemas de información culturales que se sustentan bajo la 
tecnología web, a través de distintos tipos de portales culturales. Estos nuevos espacios se desmarcan de los tradicionales portales de instituciones clásicas de la cultura como son archivos, museos y bibliotecas, constituyéndose como puntos de acceso a la información actual y actualizada en materia cultural para el público en general y, como herramienta de apoyo para los profesionales de los sectores culturales, principalmente, de la música y artes escénicas, fomentando la cooperación y colaboración en el intercambio de información especializada entre los agentes culturales más desfavorecidos, además de proporcionar una relevante difusión de la cultura regional proyectada a través de productos ofertados en dichos portales.

\section{Notas}

(1) El gasto público en cultura durante 2006 fue, en relación al P.I.B. un $0,09 \%$ en la Administración del Estado, un 0,18 en la Administración Autonómica y un $0,33 \%$ en la Administración Local.

(2) Web: http://www.cool-tura.es

(3) La guía Go! (http://www.laguiago.com/), vende contenido a portales turísticos y culturales, incluyendo los de tipo público.

\section{Referencias}

Castellanos Ribot, Alfonso, (2004). El sistema de información cultural de México. // Boletín GC: Gestión Cultural. 7 (2004). http://www.gestioncultural.org/gc/boletin/pdf/ Indicadores/ACastellanos.pdf (2009-04-15).

Culture.Mondo, (2005). Portales culturales: puertas de entrada a comunidades globales. http://www.culture mondo.org/files/culturemondo-docto-base-esp.pdf (2009 -04-29).

Martinell, Alfons (1999). Los agentes culturales ante los nuevos retos de la gestión cultural. // Revista Iberoamericana de Educación. 20 (1999). http://www.rieoei. org/rie20a09.htm (2009-03-04).

Ministerio de Cultura (2008). CULTURAbase: sistema de difusión de estadísticas culturales. 2008. http://www.mcu.es/culturabase/ (2009-05-13).

Rodríguez Motaró, Arturo (2007). La sociedad de la cultura. Barcelona: Ariel, 2007 